\title{
Serum Fibrinogen Profile In Neonatal Septicemia.
}

\author{
Abhay Charan Pal ${ }^{1}$, Dipta Kanti Mukhopadhyay², Panchanan Kundu ${ }^{3}$. \\ ${ }^{1}$ Assistant Professor; Department of Pediatric Medicine, B.S.Medical College, Bankura, W.B. \\ ${ }^{2}$ Assistant Professor; Department of Community Medicine, B.S. Medical College, Bankura, W.B. \\ ${ }^{3}$ Professor, Department of Anatomy; B.S. Medical College, Bankura, W.B.
}

\begin{abstract}
Introduction: Septicemia is a major cause of mortality in neonates. One of the major problems is non-availability of any sensitive and specific test for early diagnosis. So a number of adjunctive tests including serum fibrinogen level were evaluated.
\end{abstract}

Objective: 1) to note the alteration of serum fibrinogen level in neonatal septicemia.

2) To Study its diagnostic and prognostic implication.

Materials \& Methods: 60 cases of neonatal septicemia diagnosed by "sepsis screen" were compared with 60 matched controls with respect to their serum fibrinogen level on two occasions: one on admission and other after attaining age of $\sigma^{\text {th }}$ day whenever applicable. The titre taken in first 5 days of life was termed as Day ' 0 ' value and titre taken $6^{\text {th }}$ day onward was termed as $\geq 6^{\text {th }}$ day PNA value. The sensitivity of serum fibrinogen as diagnostic test was evaluated compared to "sepsis screen" It's value as a prognostic marker was also estimated.

Results: The serum fibrinogen level in septicemic neonates was significantly higher than controls both in term and pre-term neonates and the elevation was consistent in both occasions. The hypofibnogenemic $(<200 \mathrm{mg} / \mathrm{dL})$ septicemic neonates showed significantly higher mortality and higher bleeding manifestations than nonhypofibrinogenemic $(\geq 200 \mathrm{mg} / \mathrm{dL})$ septicemic neonates. The serum fibrinogen level showed a sensitivity to diagnose neonatal septicemia in a range of $66.7 \%$ to $83 \%$.

Conclusion: Serum fibrinogen level could act as diagnostic and prognostic markers of neonatal septicemia along with other clinical and laboratory parameters.

Key Words: Neonatal septicemia, fibrinogen, sepsis screen.

Running: Serum Fibrinogen profile in neonatal septicemia.

\section{Introduction:}

Septicemia has remained a major cause of mortality in the neonates both in developing as well as developed world in spite of evolution of so many potent antimicrobial agents and advanced neonatal life support care. Incidence of neonatal sepsis ranges from 1 to 14 per 100 live births in different studies but community incidence is much higher due to gross under reporting. Septicemia accounts for 6-10\% of perinatal death and $20 \%$ of neonatal deaths in hospital-based study. The mortality of neonatal sepsis has remained almost unchanged in last two decades. One important cause among many others is non-availability of any specific and sensitive test for early diagnosis and non specific early clinical signs $(1,2,3)$.

Though isolation of organism from central body fluids is still the most specific test and gold standard to diagnose neonatal sepsis, the main problem is that the culture result is not available before $48-72$ hours and in a number of cases no bacteria could be isolated from blood even in highly suspected cases of sepsis where early initiation of potent antibiotic is important for favourable outcome. Due to these limitations a number of adjunctive tests have been evaluated for prompt diagnosis of neonatal septicemia with certainty . Some of these tests have very high sensitivity and negative predictive value almost approaching $100 \%$ viz. IT ratio, Creactive Protein and neutropenia $(<1750 / \mathrm{cmm})(1,3,4,5)$

Estimation of alteration of serum fibrinogen and other coagulation profile as adjunctive test has drawn interest of many workers since long time. Fibrinogen, factor 1 of coagulation cascade is a soluble glycoprotein. In response to any inflammatory stress there is an activation of haemostatic mechanism as well as enhanced synthesis of fibrinogen in liver. In decompensate stress viz. advanced sepsis, there is intense stimulation of fibrinolytic mechanism causing a fall in fibrinogen and activation of disseminated intra-vascular coagulation (DIC). There is transient elevation of serum fibrinogen level immediately after birth which declines to normal adult level during first 24 hours and latest by $5^{\text {th }}$ day of life. However in presence of septicemic process the fibrinogen level does not come down to normal level rather it remains elevated sometimes very high. The present study is directed to note alteration in serum fibrinogen level in septicemic neonates. 


\section{Materials \& Methods:}

A case-control study was carried out in the Pediatric Ward, B.S. Medical College, Bankura from June 2011 to February 2012. Study population included the neonates admitted to the pediatric ward during the study period.

Cases were selected from neonates admitted consecutively in the ward during the study period with any combination of clinical features mentioned here under and subsequently fulfilled any two of the five laboratory parameters and were taken as cases of possible sepsis.

Clinical features: Poor feeding, poor activity, thermal instability, respiratory distress, abdominal distention, bulging fontanalle, altered sensorium, abnormal cry and convulsion.

Laboratory parameters:

1. WBC count $<5000 / \mathrm{cmm}$ on admission

2. Micro ESR $>15 \mathrm{~mm}$ in $1^{\text {st }}$ hour or $\geq($ Day of life +3$) \mathrm{mm} /$ hour

3. Neutropenia $<1750 / \mathrm{cmm}$

4. Positive C-reactive protein (i.e. $\mathrm{CRP} \geq 6 \mathrm{mg} / \mathrm{L}$ )

5. Immature \& Total neutrophil (I.T) ratio $>0.2$ on admission

These diagnostic criteria accepted as guidelines for diagnosis of neonatal sepsis are termed as 'sepsis screen' $3,5,10$

\section{Study Plan:}

Controls were post natal age and gestational age matched neonates without any clinical features suggestive of possible sepsis. A total of 60 cases and 60 controls were recruited in the study. Detailed history of presenting illness, duration of illness, ante-natal, intra-natal and postnatal events were recorded on admission in both cases and controls. Venous blood samples of neonates selected as case after being screened by clinical and laboratory examination were sent for culture and drug sensitivity testing. The cerebro-spinal fluid (CSF) was also sent on admission and whenever meningeal involvement was suspected. The neonates suffering from possible sepsis were treated as per standard guidelines. Suitable modifications were made based on culture and drug sensitivity report and clinical course.

Serum fibrinogen levels were estimated in both cases and controls on two occasions: once before sixth day of life (Day ' $\mathrm{O}$ ' value) and another on or after $6^{\text {th }}$ day of life $\left(\geq 6^{\text {th }}\right.$ Day PNA value) considering that in all neonates serum fibrinogen level came to normal 'adult' value by $6^{\text {th }}$ day of life in absence of sepsis 1,30 , 3 neonates were admitted on or after $6^{\text {th }}$ day of life and so their serum fibrinogen level were estimated once $\left(\geq 6^{\text {th }}\right.$ Day PNA value) as in other 7 neonates who were admitted during 0-5 days of life and died before $6^{\text {th }}$ day of life (only Day 'O' values were taken).

\section{Laboratory Method:}

1. Total leukocyte count, differential leukocyte count, immature neutrophil count and its ratio with total neutrophil, toxic granules in neutrophil were examined manually in a standardized laboratory of B.S. Medical College, Bankura by expert of clinical hematology.

2. Micro ESR was also measured manually with microhematocrit tube.

3. C - reactive protein was tested with Avitax -CRP rapid latex agglutination test kit.

4. Blood cultures were initially done in glucose broth and subcultures were done on blood agar, chocolate agar, Maconkey agar and standard technique were used to identify organism.

5. CSF study was done using standard procedure in Central Pathology department.

6. Serum fibrinogen level was estimated using auto-analyzer (AUTOLAB-Boehringer Mannheim Ltd.) (12).

' $Z$ ' tests were applied to determine any difference of serum fibrinogen level between septicemic neonates and healthy neonates.

The study protocol got clearance from Institutional Ethics Committee of B.S. Medical College, Bankura.

Results: 60 neonates were recruited as cases of which 35 were male and 25 were female. The average weight of septicemic neonates under study was $2.175 \pm 0.495 \mathrm{~kg}$. The age of onset of $80 \%$ study neonates were more than 3 days; however $50 \%$ admitted before $6^{\text {th }}$ day of life.

Table - 1: Frequency of signs and symptoms in septicemic neonates on admission.

\begin{tabular}{|l|l|l|l|}
\hline Signs and Symptoms & No. $(\%)$ & Signs and Symptoms & No.(\%) \\
\hline Poor feeding & $50(83.3)$ & Hepatomegaly & $24(40.0 \%)$ \\
\hline Fever & $24(40.0)$ & Cold extremities & $28(46.6)$ \\
\hline Respiratory distress & $36(60.0)$ & Hypertonia & $12(20.0)$ \\
\hline Abdominal distention & $32(53.3)$ & Hypotonia & $25(41.6)$ \\
\hline Apnea & $18(30.0)$ & Bulged fontanel & $4(6.6)$ \\
\hline Convylsions & $8(13.3)$ & Sclerema & $10(16.6)$ \\
\hline Jaundice & $20(33.3)$ & $\begin{array}{l}\text { Cutaneous \& mucosal } \\
\text { bleeding }\end{array}$ & $18(30.0)$ \\
\hline
\end{tabular}


Poor feeding, respiratory distress, abdominal distention, hepatomegaly, cold extremities and hypotonia are the most common presentation in septicemic neonates.

Among 60 cases of possible sepsis, Gram positive bacteria were isolated in 24 cases and Gram negative bacteria were isolated from 18 cases as causative organism. In total blood culture confirmed 42 cases of neonatal septicemia.

Table -2: Sensitivity of adjunctive tests

\begin{tabular}{|l|l|l|l|}
\hline Test & Positive $*$ & Negative $* *$ & Sensitivity \\
\hline I:T ratio of neutrophil $(>0.2)$ & 36 & 16 & 85.7 \\
\hline CRP $(\geq 6 \mathrm{mg} / \mathrm{L})$ & 28 & 14 & 66.7 \\
\hline Micro ESR $\left(\geq 15 \mathrm{~mm}\right.$ in $1^{\text {st }}$ hr or $($ day +3$\left.) / \mathrm{hr}\right)$ & 26 & 16 & 61.9 \\
\hline
\end{tabular}

*Blood culture positive $\mathrm{A}=42 ; * *$ Blood culture negative $\mathrm{B}=18$.

CSF profile was suggestive of meningeal involvement in 14 cases out of which 8 developed neurological manifestations.

Table -3: Serum fibrinogen levels of septicemic and control neonates.

\begin{tabular}{|c|c|c|}
\hline & Day 'O' value (mg/dl) & $\geq 6^{\text {th }}$ Day PNA value (mg/dl) \\
\hline Cases & $433.533 \pm 280.058$ & $550.868 \pm 286.134$ \\
\hline Controls & $242.933 \pm 37.376$ & $253.226 \pm 43.393$ \\
\hline$Z$ & 3.69 & 7.49 \\
(p value) & $\mathrm{P}<0.000 .1$ & $\mathrm{P}<0.00001$ \\
\hline
\end{tabular}

Table -3 showed that septicemic neonates had significantly higher level of serum fibrinogen compared to their control in both Day ' $O$ ' value and $\geq 6^{\text {th }}$ Day PNA value.

Table -4: Serum fibrinogen level of cases according to the gestational age.

\begin{tabular}{|l|l|l|l|l|}
\hline \multirow{2}{*}{} & \multicolumn{2}{|c|}{ Day 'O' } & \multicolumn{2}{c|}{$\geq 6^{\text {th }}$ Day PNA } \\
\cline { 2 - 5 } & No. & Value $(\mathrm{mg} / \mathrm{dL})$ & No. & Value $(\mathrm{mg} / \mathrm{dL})$ \\
\hline Term & 14 & $369.642 \pm 185.881$ & 25 & $548.08 \pm 273.501$ \\
\hline Pre-term & 16 & $489.437 \pm 332.689$ & 28 & $553.357 \pm 301.953$ \\
\hline $\begin{array}{c}\mathrm{T} \\
\text { (p value) }\end{array}$ & & 1.19 & & 0.07 \\
$\mathrm{n}$ & $\mathrm{P}=0.243$ & $\mathrm{P}=0.947$ \\
\hline
\end{tabular}

It was evident from table -4 that there was no significant difference in serum fibrinogen level in both Day ' $\mathrm{O}$ ' value and $\geq 6^{\text {th }}$ Day PNA value between term and pre-term neonates with sepsis. However, term neonates showed significant rise between Day ' $O$ ' value and $\geq 6^{\text {th }}$ Day PNA value $(t=2.17 ; p=0.036)$.

Tables -5: Serum fibrinogen level of controls according to the gestational age.

\begin{tabular}{|c|l|l|l|l|}
\hline \multirow{2}{*}{} & \multicolumn{2}{|c|}{ Day 'O' } & \multicolumn{2}{c|}{$\geq 6^{\text {th }}$ Day PNA } \\
\cline { 2 - 5 } & No. & Value (mg/dL) & No. & Value (mg /dL) \\
\hline Term & 14 & $242.071 \pm 29.034$ & 25 & $262.88 \pm 44.44$ \\
\hline Pre-term & 16 & $243.687 \pm 41.436$ & 28 & $244.607 \pm 41.315$ \\
\hline $\begin{array}{c}\text { T } \\
\text { (p value) }\end{array}$ & 0.12 & 1.55 \\
$\mathrm{P}=0.904$ & $\mathrm{P}=0.127$ \\
\hline
\end{tabular}

Table -5 revealed no significant difference in serum fibrinogen level between term and pre-term controls not even between Day ' $O$ ' value and $\geq 6{ }^{\text {th }}$ Day PNA value.

Among 60 cases, 13 septicemic neonates had serum fibrinogen level less that $200 \mathrm{mg} / \mathrm{dL}$ in either of the two occasion and 6 had more than $1000 \mathrm{mg} / \mathrm{dL}$.

The sensitivity of serum fibrinogen level to diagnose neonatal septicemia was also determined compared to blood culture. The mean +2 SD of the control was taken as 'cut-off' value for diagnosis of septicemia both in Day ' $O$ ' value and $\geq 6^{\text {th }}$ Day PNA value. The cut-off value for neonates with age of $0-5$ days: $316.5 \mathrm{mg} / \mathrm{dL}$ and the cut-off value for neonates with age $6^{\text {th }}$ day or more: $339.9 \mathrm{mg} / \mathrm{dL}$. The $\geq 6^{\text {th }}$ Day PNA value showed higher sensitivity than Day ' $O$ ' value as evident in table-6.

Table-6: Sensitivity of serum fibrinogen level compared to sepsis screen

\begin{tabular}{|l|l|l|l|}
\hline Test value & Positive & Total & Sensitivity \\
\hline Day 'O' value & 20 & 30 & 66.7 \\
\hline$>6^{\text {th }}$ Day PNA value & 44 & 53 & 83.0 \\
\hline
\end{tabular}

Table-7 showed that serum fibrinogen titre less that $200 \mathrm{mg} / \mathrm{dL}$ in any of the two occasions was significantly associated with mortality in septicemic neonates. Other neonatal variables were not significantly associated with mortality in neonatal septicemia. 
Table-7: Distribution of deaths according to Serum fibrinogen level.

\begin{tabular}{|c|c|c|c|}
\hline Serum fibrinogen level & No. of cases & No. of deaths (\%) & $\begin{array}{l}\text { Likely hood ratio } \mathrm{X}^{2}(\mathrm{P} \\
\text { value) }\end{array}$ \\
\hline$<200 \mathrm{mg} / \mathrm{dL}^{*}$ & 13 & $10(76.9)$ & 13.947 \\
\hline$\geq 200 \mathrm{mg} / \mathrm{dL} \mathrm{\#}$ & 47 & $2(4.3)$ & $\begin{array}{l}\text { (Yates' corrected) } \\
0.0001\end{array}$ \\
\hline
\end{tabular}

* in either of the two observation

\# in both the occasion

According to table-8, the bleeding manifestations in septicemic neonates were significantly associated with serum fibrinogen level less that $200 \mathrm{mg} / \mathrm{dL}(\mathrm{t}=12.219 ; \mathrm{p}<0.0001)$.

Tables-8: Distribution of bleeding manifestations according to serum fibrinogen level

\begin{tabular}{|l|l|l|}
\hline Serum fibrinogen level & No. of cases & No. of bleeding manifestations (\%) \\
\hline$<200 \mathrm{mg} / \mathrm{dL} *$ & 13 & $12(92.3)$ \\
\hline$\geq 200 \mathrm{mg} / \mathrm{dL} \#$ & 47 & $6(12.8)$ \\
\hline
\end{tabular}

* in either of the two observation

\# in both the occasion

\section{Discussion:}

In the present study, septicemic neonates showed consistent elevation of serum fibrinogen level in Day ' $O$ ' value and $>6^{\text {th }}$ Day PNA value than age, sex and gestational age matched controls both in term and pre-term neonates (Table-3,4,5). Kirsch et al. noted that in neonatal shock, sepsis and hypoxia, certain fatameters of haemostatic system including fibrinogen provided information about the course of disease. Weissbach et al. also corroborated the findings.

However, Becht and Semard found that serum fibrinogen levels lagged behind the development qf5an inflammatory process and in their opinion, this parameter should not be relied on for early evidence of infection. Speer et al. in an intention to evolve early diagnostic markers in neonatal septicemia and/ or meningitis recorded that immature to total (I:T) ratio of neutrophil and C-rałctive protein were better laboratory, markers of neonatal sepsis than fibrinogen but the latter showed some elevation in sepsis.

Aldridge et al. recorded significant elevation of serum fibrinogen level in neonatal sepsis which conformed to the present study. Other studies als corroborated the fact. Kvasnicka et al. reported significant elevation of serum fibrinogen to any stressfúf condition viz. infection, trauma etc. compared to healthy control. Baskurt et al in rat model demonstrated the same findings.

It was also obsefyed in this study that serum fibrinogen level had definite prognostic significance showing higher mortality ${ }^{1}$ in hypofibrinogenemic neonates (sertm fibrinogen level $<200 \mathrm{mg} / \mathrm{dL}$ ) than in nonhypofibrinogenemic neonates (serum fibrinogen level $\geq 200 \mathrm{mg} / \mathrm{dL}$ ). Out of sixty septicemic neonates, thirteen had serum fibrinogen level less than $200 \mathrm{mg} / \mathrm{dL}$ at any point of their illness and ten out of thirteen died showing almost $77 \%$ mortality. On the other hand, out of forty seven non-hypofibrinogenemic neonates with sepsis only two died giving a mortality rate of $4 \%$ and the difference is significant. Activation of fibrinolytic activity with low fibrinogen level is an indicator of decompensated haemostatic system which is associated with poor prognosis. The septicemic neonates with serum fibrinogen level less than $200 \mathrm{mg} / \mathrm{dL}$ at any point of their illness developed bleeding manifestation more frequently than other septicemic neonates. Twelve out of thirteen hypofibrinogenemic neonates developed bleeding manifestations compared to six out of forty seven nonhypofibrinogenemic neonates and the association between hypofibrinogenemia and bleeding manifestations were significant. Bach-Gansmo et al. showed that in advanced and severe sepsis there was activation of fibrinogen degradation products. Pedrinelli et al. in a different setting reported that serum fibrinogen level could correlate well with mortality.

Martinez et al. studied intensively the role of different parameters of coagulation in neonatal sepsis. Fibrinogen level in septicemic neonates was significantly higher than healthy controls. They also documented that markers of the activation of coagulation including fibrinogen also remained high in the survivor group whereas the non-survivor consistently displayed evidence of activation of fibrinolytic system. They concluded that the early sepsis was characterized by activation of coagulation system with high titre of fibrinogen and mortality was associated with low fibrinogen level due to intense fibrinolytric activity. Mikic et al. also reported negative correlation between mortality and serum fibrinogen level on admission in septicemic neonates. Mavrammatis et al. reported that in early sepsis two parameters of coagulation activation were changed: decrease in factor XII and increase in fibrinogen. However in severe sepsis and septic shock coagulation were markedly decreased irrespective of causative organism. 
"Sepsis screen" parameters were considered useful adjunctive test for diagnosis of neonatal sepsis and demonstrated high sensitivity in the present study also. The sensitivity ranged from $61.9 \%$ in Micro ESR to $85.7 \%$ in I:T ratio which corroborated by other researchers.

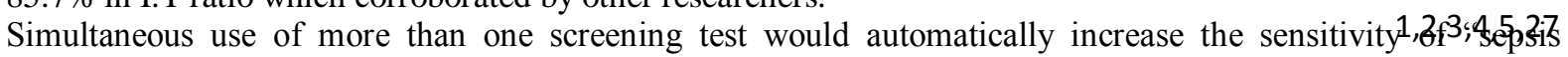
screen".

Role of serum fibrinogen level as a marker of neonatal septicemia in addition to other adjunctive tests was also tried to be elucidated in this study. Sensitivity of serum fibrinogen elevation was estimated using "mean + 2SD" value as "cut-off". It was seen that the sensitivity of this test as a diagnostic parameter was in the range of $66.7 \%$ (Day ' $\mathrm{O}$ ' value) and $83 \%\left(\geq 6^{\text {th }}\right.$ Day PNA value) taking "sepsis screen" as gold standard. This finding w⿶s 160 nsistent with the finding in other studies.

\section{Conclusion:}

Efforts to elucidate alteration in the hemostatic and fibrinolytic parameters in neonatal sepsis are a relatively new area. The study was undertaken with a desire to find out alteration in serum fibrinogen level in neonatal septicemia and to demonstrate the diagnostic and prognostic significance of this alteration. Further studies in this issue will add to more elaborate understanding of this parameter and its role in neonatal sepsis.

Competing interest: The authors declare that they have no competing interest.

Authors contribution: A.C. Pal actually conducted the study, drafted the manuscript, revised it critically for important intellectual content.

D.K. Mukhopadhyay performed the data analysis and interpretation.

P. Kundu finally revised the manuscript and provided all sorts of co-operation during the study.

\section{Acknowledgement:}

To all nursing staffs and other personnels of the nursery, BSMCH but for whose co-operation it would have been difficult to complete the study.

To all staffs of Department of Pathology, Microbiology and Biochemistry whose help was crucial for the laboratory work.

\section{Reference:}

[1]. Forfar and Arneil's Texbook of Pediatrics. $7^{\text {th }}$ edition. 2010. pp 275282

[2]. Nelson Texbook of Pediatrics. $19^{\text {th }}$ edition. 2011. pp $538-552$

[3]. Cloherty J.P. Stark A R. Manual of Neonatology. $7^{\text {th }}$ edition. 2012. pp 271291

[4]. Dutta A K. Newer concepts in the diagnosis and management of neonatal sepsis. In the commemorative volume published on the occasion of MILLENNIUM PEDICON CALCUTTA - 2000. pp 1-8.

[5]. Sharma A, Krishna Kutty CV, Sabharwal U et al. Evaluation of Sepsis Screen for diagnosis of neonatal septicemia. Indian Peditr. 1993; 60: $559-563$.

[6]. Nathan and Oski. Hematology of Infancy and Childhood. $4^{\text {th }}$ edition. 1993. pp $118-119$.

[7]. Ries M, Klings J, Rauch R, Zenker M. Changes in the activation markers of blood coagulation and fibrinolysis in the neonatal period. Klin Pediatr. 1996; 208 (6): 350-354.

[8]. The Development of Human Coagulation System in fullterm neonates. Blood. 1987; $70: 165$

[9]. Zipursky A, Jabar HM. The Hematology of bacterial infections in neonatal period. Clinical Hematology. $1978 ; 7: 175$.

[10]. Jeffrey GS. Clinico-pathologic approach to the diagnosis of Neonatal Sepsis. Clin Perinatol. 1991; $18(2): 361-381$.

[11]. Alder MS, Ronald DL. The erythrocyte sedimentation rate in newborn period. J Peditr. 1975; 86(6): $942-948$.

[12]. Harold Varley's Practical Clinical Biochemistry. $5^{\text {th }}$ edition. Pp426-427; 557-558.

[13]. Kirsch W, Buttner M, Wenzel E. diagnostic therapeutic problems of defibrination syndrome in shock, sepsis and neonatal hypoxia. Monatsschr Kinderheilkd. 1997; 125(6): 621-627.

[14]. Weissbach G, Domula M, handrick W, Effect of hemostasis and thrombogenesis by septic processes especially in childhood. J Gesmte Inn Med. 1984;39(10): 214-219.

[15]. Speer CP, Gahr M, Schroter W. Early diagnosis of neonatal infection. Monatsschr Kinderheilkd. 1985;133(9): 665-668

[16]. Becht JL, Semard SD. Hematology, blood typing and immunology of the neonatal foal. Vet Clin North Am Equine Pract. 1985; 1(1): $91-116$.

[17]. Aldridge BM, Garry FB, Adams R. neonatal septicemia in calves. J Am Vet Med Assoc. 1993; $203(9)$ : 1324 -1329.

[18]. Barton MH, Morris DD, Norton N, Prasse KW. Hemostatic and fibrinolytic indices in neonatal foals with presumed septicemia. J Vet Int Med 1998; 12(1): 26-35.

[19]. Kvasnicka J, Brija J, Krska Z, Kudrna K, Peskova M, Pecen L. Increase in soluble cytoadhesive molecules SE-selection and SICAM-1 and hyperfibrinogenemia in patients with polytrauma. Sbornik Lekarsky. 1998.99(2): 93-96.

[20]. Baskurt OK, Temiz A, Meiselman HJ. Red blood cell aggregation in experimental sepsis. Journal of Laboratory and Clinical Medicine 1997; 130(2): 183-190.

[21]. Bach-gansomo ET, Gobal HC $<$ Skjonsberg OH. Degradation of fibrinogen and cross-linked firrin by human neutrophil elastase generates D-like fragments detected by ELISA. Thrombosis Research. 1998; 92(3): 125-134.

[22]. Pedrinelli R, Barchielli A, Barchielli R, Meliollo E, Ferrari M, Fibrinogen and mortality in chronic limb ischemia. J Int Med. 1999; 245(1): 75-81.

[23]. Martinez MA, Pena JM, Fernandez A, Jimenez M, Vazquezz JJ. Time course and prognostic significance of hemostatic markers in sepsis. Critical Care Medicine. 1999; 27(7): 1303-1308.

[24]. Mikic D, Bijik I, Rajic- Dimitrijevic R, Truzac Z, Begovic V, Dramanic S, Significance of determination of certain clinical and laboratory parameters in the evaluation of severity and outcome in sepsis. Vojnosanitetski Pregled. 1999; 56(6): 607-617.

[25]. Mavrommatis AC, Theodoridis T, Orfanidou A, Roussos C, Zakynthinos S. Coagulation system and platelets are fully activated in uncomplicated sepsis. Critical Care Medicine. 2000; 28(2): 451-457.

[26]. Philip AGS, Hewitt JR. Early diagnosis of neonatal sepsis. Pediatr, 1980;65:1030-1041. 